\title{
STUDI KASUS KEMIRINGAN GEDUNG 4 LANTAI AKIBAT KEGAGALAN FONDASI DI PANGKAL PINANG
}

\author{
Orlando $^{1}$, dan Gregorius Sandjaja Sentosa ${ }^{2}$ \\ ${ }^{1}$ Program Studi Sarjana Teknik Sipil, Universitas Tarumanagara, Jl. Letjen S. Parman No.1 Jakarta \\ orlandosucipto@gmail.com \\ ${ }^{1}$ Program Studi Sarjana Teknik Sipil, Universitas Tarumanagara, Jl. Letjen S. Parman No.1 Jakarta \\ gregoriuss@ft.untar.ac.id
}

Masuk: 12-07-2021, revisi: 06-08-2021, diterima untuk diterbitkan: 19-08-2021

\begin{abstract}
A fourstorey building, located in Bangka Island, has been experiencing tilting for \pm 5 years and based on manually measuring the building has tilted about $\pm 1-2^{0}$. This building was analysed to find the possibility cause of the tilting. The bearing capacity and settlement of the building were analysed by making several simulations. Based on an interview with the owner there were limited information known. The limited data identified are no soil test data available, the depth foundation of bored pile unknown, the detail structures of the building were assumed based on sight. Therefor to analyse the tilting of the building some assumptions have been made. After analysis it was found the possibility of the tilting caused by the exaggerated differential settlement of the building. The left hand side, eyed from the front of the building, has been settled up to more than $20 \mathrm{~cm}$, while the right hand side of the building the possibility of settlement less then $10 \mathrm{~cm}$. There is a possibility that will be a reduction in the building load due to the presence of other buildings adjacent to the analyzed building. The bearing capacity seems does not have a dominant role causing the tilting.
\end{abstract}

Keywords: soil bearing capacity; Settlement; Pile Cap; Bore Pile, differential settlement.

\begin{abstract}
ABSTRAK
Bangunan empat lantai di Pulau Bangka telah mengalami kemiringan selama \pm 5 tahun dan berdasarkan pengukuran manual bangunan telah miring sekitar \pm 1 -2 derajat setelah diukur secara manual. Bangunan ini dianalisis penyebab terjadinya kemiringan. Perhitungan daya dukung dan penurunan telah dilakukan untuk mencari penyebab terjadinya kemiringan bangunan. Berdasarkan wawancara dengan pemilik, informasi yang diperoleh terbatas. Kesulitan dalam menganalisis kasus ini adalah tidak tersedianya data penyelidikan tanah, ukuran dan kedalaman fondasi tiang bor tidak diketahui, serta data-data desain struktur bangunan diasumsikan berdasarkan pengelihatan. Dalam melakukan analisis kemiringan bangunan ini telah digunakan serangkaian asumsi untuk mencari penyebab terjadinya penurunan. Dari analisis ditemukan bahwa yang paling memungkinkan terjadi adalah perbedaan penurunan yang berlebihan. Jika dilihat dari depan bangunan, penurunan bagian kiri bangunan kemungkinan telah turun lebih dari $20 \mathrm{~cm}$, sementara bagian kanannya turun kurang dari $10 \mathrm{~cm}$. Ada kemungkinan terjadi reduksi beban bangunan karena adanya bangunan lain yang berdempetan dengan bangunan yang di analisis. Daya dukung fondasi nampaknya tidak menyebabkan penurunan bangunan ini.
\end{abstract}

Kata Kunci: Daya Dukung Tanah; Penurunan Tanah; Pile Cap; Bore Pile, perbedaan penurunan

\section{PENDAHULUAN}

Dalam pembangunan suatu bangunan, hal pertama yang dilaksanakan di lapangan adalah pekerjaan fondasi (sub structure), setelah itu dilanjutkan dengan pekerjaan struktur atas (upper structure). Fondasi adalah struktur bagian bawah bangunan yang berhubungan langsung dengan tanah, atau bagian bangunan yang terletak di bawah permukaan tanah yang mempunyai fungsi memikul beban bagian bangunan lainnya di atasnya. (Solikhati, 2011). Fondasi merupakan salah satu faktor terpenting dalam sebuah kekuatan bangunan, apabila fondasi tidak kuat menahan beban bangunan maka kemungkinan bangunan akan roboh. Oleh sebab itu, fondasi harus didesain dan dihitung secara teliti. Bangunan yang akan dianalisis pada penelitian ini merupakan bangunan 4 lantai yang terletak di wilayah Kota Pangkal Pinang, Kepulauan Bangka Belitung. Bangunan tersebut sudah berdiri selama \pm 5 tahun. Kemiringan bangunan diukur secara manual menggunakan bandul tukang (lot), benang tukang (benang karung), dan busur derajat yang akhirnya menyimpulkan kemiringan bangunan sebesar $\pm 1-2{ }^{0}$. Kemiringan bangunan dapat di lihat pada Gambar 1 . 


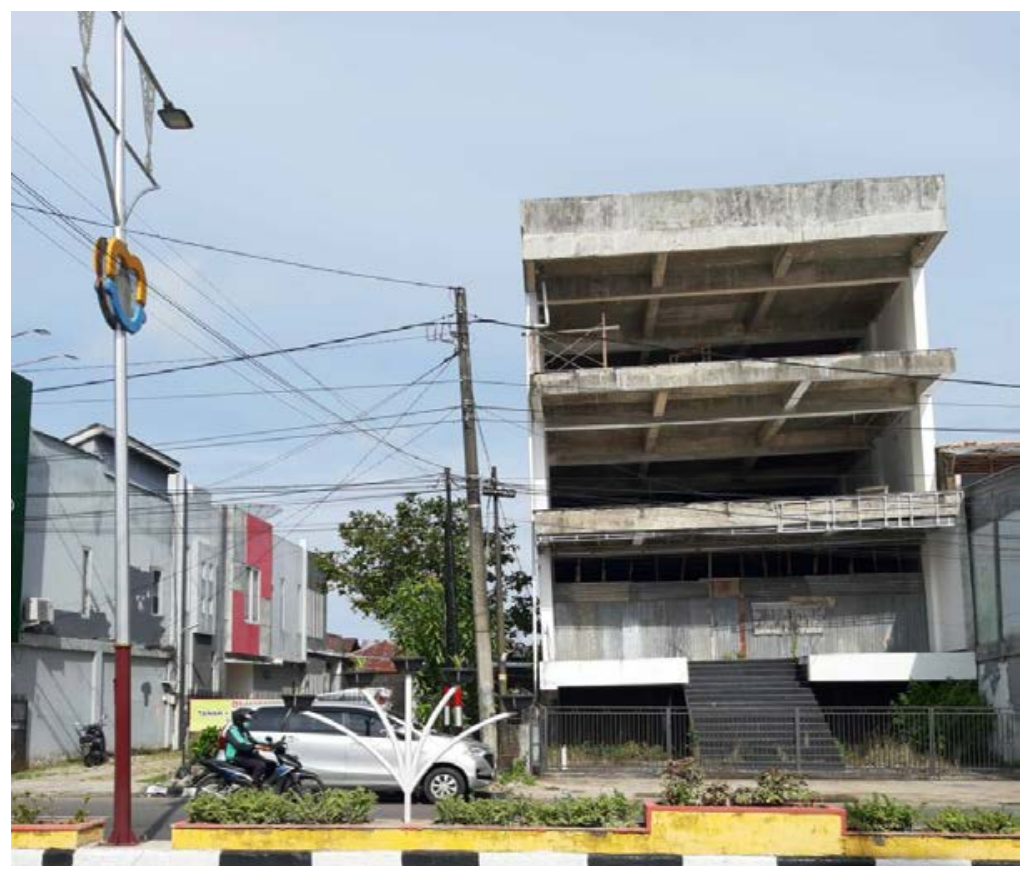

Gambar 1. Bangunan tampak depan

Penelitian ini akan membahas mengenai analisis penyebab terjadinya kemiringan pada bangunan. Karean terbatasnya data yang diperoleh dari bangunan ini, maka serangkaian asumsi dilakukan untuk analisis. Data tanah diambil dari data penyelidikan tanah yang ditemukan di sekitar lokasi, kedalaman fondasi tiang bor dan diameternya diasumsikan, berat bangunan juga diasumsikan berdasarkan pengamatan,

\section{Fondasi tiang bor}

Fondasi tiang bor adalah salah satu dari beberapa jenis fondasi dalam (deep foundation) yang pemasangannya dilakukan dengan mengebor tanah terlebih dahulu. Penerapan fondasi tiang bor ke dalam tanah dilakukan dengan cara mengebor tanah terlebih dahulu, yang kemudian diisi tulangan besi yang telah dirangkai lalu dicor dengan beton. Fondasi tiang bor ini digunakan untuk menjaga kestabilan dan kekuatan lereng dinding penahan tanah termasuk pada fondasi bangunan ringan yang dibangun di atas tanah lunak dan struktur yang membutuhkan gaya lateral yang cukup besar. Fondasi bored pile digunakan apabila tanah dasar yang kokoh yang mempunyai daya dukung besar terletak cukup dalam.

\section{Daya dukung tiang bor}

Daya dukung tiang bor dihitung menggunakan rumus Reese \& Wright, Meyerhof dan metode lamda ( $\lambda$ ) (Das, 2011). Data tanah yang digunakan berasal dari data sekunder tanpa data lab. Data tanah yang di ambil berjarak $\pm 100 \mathrm{~m}$ dari lokasi bangunan yang akan dianalisi. Data tanah yang digunakan merupakan hasil interprestasi data tanah yang dapat di lihat pada tabel 1 .

Tabel 1. Hasil interprestasi data tanah

\begin{tabular}{cccccccc}
\hline \multicolumn{3}{c}{ Data Lapangan } & \multicolumn{5}{c}{ Data Korelasi } \\
\hline Kedalaman (m) & Jenis Tanah & N-SPT & Gs & e & w $(\%)$ & Cu $(\mathrm{kN} / \mathrm{m} 2)$ & $\gamma_{\text {sat }}(\mathrm{kN} / \mathrm{m} 3)$ \\
\hline $0,0-5,50$ & Lempung & 6 & 2,715 & 1,15 & 40 & 36 & 17,63 \\
$5,5-7,7$ & Lanau & 7 & 2,65 & 1,15 & 15 & 50 & 21,36 \\
$7,7-11,0$ & Lempung & 9 & 2,715 & 1,15 & 40 & 60 & 17,63 \\
$11,0-15,0$ & Lempung & 26 & 2,715 & 1,15 & 40 & 180 & 17,63 \\
$15,0-28,0$ & Lempung & 60 & 2,715 & 1,15 & 40 & 375 & 17,63 \\
$28,0-30,0$ & Lempung & 60 & 2,715 & 1,15 & 40 & 375 & 17,63 \\
\hline
\end{tabular}

(Yusti \& Fahriani, 2014) 
Dimana Gs $=$ berat jenis tanah, $\mathrm{e}=$ angka pori, $\mathrm{w}=$ kadar air dalam keadaan jenuh, $\mathrm{Cu}=$ Kekuatan geser dan $\gamma$ sat $=$ berat air dalam keadaan jenuh

\section{Penurunan}

Jika suatu lapisan tanah dibebani, maka tanah akan mengalami penurunan (settlement), atau boleh dikatakan tanah yang mengalami tegangan akan mengalami rengangan dalam tanah tersebut. Penurunan tanah merupakan peristiwa termampatnya suatu lapisan tanah, dapat dikarenakan beban luar atau pemompaan air. (Pranoto \& Setiabudi, 2017)

Penurunan segera adalah penurunan yang dihasilkan oleh distorsi massa tanah yang tertekan dan terjadi pada volume konstan. Menurut Janbu, Bjerrum dan Kjaemsli (Das, 2011) dirumuskan sebagai berikut:

$$
S_{i}=\mu_{i} \mu_{o} \frac{q B}{E}
$$

Dengan $\mathrm{Si}=$ Penurunan segera, $\mathrm{q}=$ Tekanan netto fondasi $(\mathrm{P} / \mathrm{A}), \mathrm{B}=$ Lebar tiang pancang kelompok, $\mathrm{E}=$ Modulus elastis, $\mu \mathrm{i}=$ Faktor koreksi untuk lapisan tanah dengan tebal terbatas $\mathrm{H}, \mu \mathrm{o}=$ Faktor koreksi untuk kedalaman fondasi Df
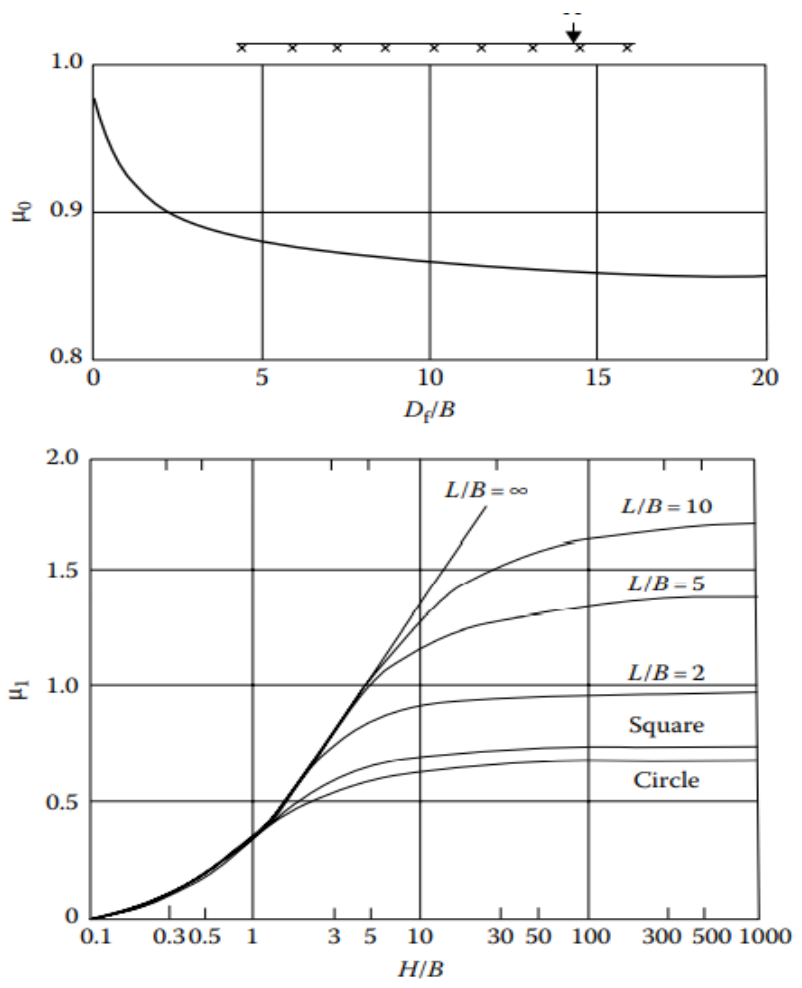

Gambar 2. Gambar grafik faktor koreksi (Das, 2011)

Penurunan konsolidasi adalah penurunan saat tanah lempung yang tersaturasi mengalami pembebanan secara konstan, akan terjadi perubahan volume akibat keluarnya air yang menempati area kosong pada lapisan tanah tersebut. Proses ini disebut konsolidasi primer. Saat sampel ditahan secara lateral, besar tekanan pori sama dengan beban yang diterima lapisan tanah yang bervariasi tergantung pada waktu dan jarak vertikal. Besar penurunan konsolidasi primer pada tanah lempung yang normally consolidated dapat dirumuskan seperti berikut:

$$
S_{p}=\frac{C_{c} H}{1+e_{o}} \log \left(\frac{\sigma^{\prime}{ }_{o}+\Delta \sigma \prime}{\sigma^{\prime}{ }_{o}}\right)
$$

Dengan $C_{c}=$ indeks pemampatan tanah, $e_{o}=$ angka pori, $H=$ tebal lapisan tanah, $\sigma^{\prime}{ }_{o}=$ tekanan overburden efektif dan $\Delta \sigma^{\prime}=$ perubahan tekanan

Bila $\sigma_{o}^{\prime}+\Delta \sigma^{\prime} \leq \sigma_{c}^{\prime}$

$$
S_{p}=\frac{C_{S} H}{1+e_{o}} \log \left(\frac{\sigma^{\prime}{ }_{o}+\Delta \sigma \prime}{\sigma^{\prime}{ }_{o}}\right)
$$

Bila $\sigma_{o}^{\prime}<\sigma_{c}^{\prime}<\sigma_{o}^{\prime}+\Delta \sigma^{\prime}$ 


$$
S_{p}=\frac{C_{S} H}{1+e_{o}} \log \frac{\sigma^{\prime} c}{\sigma_{o}{ }_{o}}+\frac{C_{c} H}{1+e_{o}} \log \left(\frac{\sigma^{\prime} o_{o}+\Delta \sigma^{\prime}}{\sigma^{\prime} o_{o}}\right)
$$

\section{STUDI KASUS KEMIRINGAN}

Data fondasi tiang bor dan jumlah tiang bor diperoleh dari wawancara kepada pemilik bangunan dan didapat bahwa kedalaman fondasi yang digunakan sedalam 6-12m dan terdapat 4 fondasi tiang bor pada 1 kolom dengan mutu beton $\left(\mathrm{fc}^{\prime}\right)=20 \mathrm{MPa}$, diameter penampang $=0,45 \mathrm{~m}$, luas penampang $=0,159043 \mathrm{~m}^{2}$, keliling penampang $=1,413717 \mathrm{~m}$, berat jenis tiang beton $=24 \mathrm{kN} / \mathrm{m}^{3}$, dan spasi tiang $=1,35 \mathrm{~m}$

\section{Daya dukung tiang bor}

Nilai daya dukung fondasi tiang diperoleh dengan menghitung daya dukung ujung dan daya dukung selimut. Daya dukung ujung didapatkan melalui rumus Reese \& Wright dan Meyerhoff sedangkan untuk daya dukung selimut tiang dihitung berdasarkan rumus Reese $\&$ Wright dan metode lamda $\lambda$. Setelah daya dukung ujung dan daya dukung selimut diperoleh maka, daya dukung akan dijumlah dan di kurangi oleh berat tiang bor dan akan dibagi safety factor untuk memperoleh daya dukung izin

Tabel 2. Daya dukung ujung tiang bor berdasarkan asumsi perhitungan dengan kedalaman tiang yang bervariasi

\begin{tabular}{ccccc}
\hline $\begin{array}{c}\text { Depth } \\
(\mathrm{m})\end{array}$ & $\begin{array}{c}\text { Qp - Meyerhoff } \\
\text { Clay/Silt }\end{array}$ & $\begin{array}{c}\text { Qp - Reese \& Wright Nspt } \\
\text { Clay/Silt }\end{array}$ & $\begin{array}{c}\text { Qp - Reese \& Wright } \\
\text { Clay/Silt }\end{array}$ & $\begin{array}{c}\text { Qp yang digunakan } \\
(\mathrm{kN})\end{array}$ \\
\hline 1 & 2 & 3 & 4 & 5 \\
\hline 0 & & 0 & 0 & 0 \\
2 & 39,2605 & - & - & - \\
4 & 78,5209 & 60,9202 & 51,5300 & 51,5300 \\
6 & 121,9411 & 76,1503 & 58,2098 & 58,2098 \\
8 & 193,7382 & 76,1503 & 69,6609 & 138,6609 \\
10 & 208,7814 & 106,6104 & 138,3675 & 200,3943 \\
12 & 283,4765 & 258,9109 & 200,3943 & 350,6901 \\
14 & 328,3456 & 258,9109 & 350,6901 & 443,7303 \\
\hline
\end{tabular}

Berdasrakan tabel 3. daya dukung ujung yang diambil adalah daya dukung terkecil dari ketiga rumus tersebut.

Tabel 3. Daya dukung selimut tiang bor

\begin{tabular}{cccccccc}
\hline $\begin{array}{c}\text { Depth } \\
(\mathrm{m})\end{array}$ & $\begin{array}{c}\Delta \text { Qs - } \\
\text { Metode } \\
\text { Lamda } \lambda\end{array}$ & $\begin{array}{c}\text { Qs - Reese \& } \\
\text { Wright Nspt } \\
(\mathrm{kN})\end{array}$ & $\begin{array}{c}\text { Qs - Reese } \\
\text { \& Wright } \\
(\mathrm{kN})\end{array}$ & $\begin{array}{c}\Delta \text { Qs - } \\
\text { Metode } \\
\text { Lamda } \lambda\end{array}$ & $\begin{array}{c}\Delta \text { Qs - Reese } \\
\text { \& Wright } \\
\text { Nspt }(\mathrm{kN})\end{array}$ & $\begin{array}{c}\Delta \text { Qs - Reese } \\
\text { \& Wright } \\
(\mathrm{kN})\end{array}$ & Qs $(\mathrm{kN})$ \\
\hline 1 & 2 & 3 & 4 & 5 & 6 & 7 & 8 \\
\hline 0 & - & - & - & - & - & - & - \\
2 & 27,83571 & 27,0756 & 24,4290 & 50,6860 & 54,1513 & 42,2419 & 54,1513 \\
4 & 36,41976 & 27,0756 & 34,6078 & 119,9269 & 108,3026 & 111,4574 & 108,3026 \\
6 & 41,37147 & 33,8446 & 37,6614 & 199,9299 & 169,2228 & 186,7802 & 169,2228 \\
8 & 61,47949 & 33,8446 & 62,7690 & 313,9658 & 236,9119 & 307,5117 & 236,9119 \\
10 & 66,4312 & 54,1513 & 69,5549 & 444,6165 & 345,2145 & 439,8355 & 345,2145 \\
12 & 138,7131 & 87,9959 & 129,7792 & 719,8309 & 487,3617 & 699,3939 & 487,3617 \\
14 & 143,1366 & 87,9959 & 173,0389 & 1003,8923 & 663,3534 & 1009,8461 & 663,3534 \\
16 & 257,83 & 223,3741 & 217,3589 & 1407,0706 & 974,7233 & 1400,2440 & 974,7233 \\
\hline
\end{tabular}

Berdasarkan tabel 4 daya dukung selimut yang diambil adalah daya dukung terkecil dari ketiga rumus tersebut. Perhitungan daya dukung ijin dapat dilihat pada tabel 5. 
Tabel 4. Daya dukung total

\begin{tabular}{ccccc}
\hline $\begin{array}{c}\text { Depth } \\
(\mathrm{m})\end{array}$ & $\mathrm{Qp}(\mathrm{kN})$ & $\begin{array}{c}\Delta \mathrm{Qs} \\
(\mathrm{kN})\end{array}$ & $\mathrm{Qu}(\mathrm{kN})$ & $\begin{array}{c}\text { Qall } \\
(\mathrm{kN})\end{array}$ \\
\hline 1 & 2 & 3 & 4 & 5 \\
\hline 0 & 0 & 0 & 0 & 0 \\
2 & - & 54,1513 & - & - \\
4 & 51,5300 & 108,3026 & 159,8326 & 38,0094 \\
6 & 58,2098 & 169,2228 & 227,4326 & 52,9087 \\
8 & 69,6609 & 236,9119 & 306,5728 & 71,6547 \\
10 & 138,3675 & 345,2145 & 483,5820 & 123,0237 \\
12 & 200,3943 & 487,3617 & 687,7560 & 183,4476 \\
14 & 350,6901 & 663,3534 & 1014,0435 & 284,5760 \\
16 & 443,7303 & 974,7233 & 1418,4537 & 411,7453 \\
\hline
\end{tabular}

Berdasrakan tabel 5 diperoleh daya dukung ijin dari daya dukung ujung dan daya dukung selimut tiang bor.

\section{Beban bangunan}

Asumsi berat bangunan dengan ukuran tebal plat lantai $130 \mathrm{~mm}$, balok induk $1050 \mathrm{~mm}$ x $550 \mathrm{~mm}$, balok anak 600 mm x 300 mm, kolom $400 \mathrm{~mm}$ x $600 \mathrm{~mm}$ dengan berat jenis beton $24 \mathrm{kN} / \mathrm{m}^{2}$. Karena kolom hanya berada di sisi bangunan maka diasumsikan berat bangunan dibagi dengan jumlah tiang kolom. Untuk perhitungan beban bangunan yang akan dihitung hanya deadload karena bangunan belum selesai $100 \%$ dan diperoleh beban perkolom sebesar 1001,6903 Kn

\section{Efisiensi dan daya dukung tiang kelompok}

Setelah daya dukung total dihitung, Langkah selanjutnya adalah untuk menentukan jumlah tiang yang diperlukan dan efesiensi nya, untuk efesiensi mengacu pada rumus efesien tiang kelompok .

Tabel 5. Efisiensi kelompok tiang

\begin{tabular}{cc}
\hline Rumus & Hasil \\
\hline Feld & 0,8125 \\
Converse - Labarre & 0,795 \\
Sederhana & 1,273 \\
Seileer Keeney & 0,8013 \\
Los Angeles Group & 0,85638 \\
\hline
\end{tabular}

Dari 5 rumus yang telah dihitung pada tabel 6, maka dipilih hasil paling minimum untuk dijadikan koefisien efesiensi kelompok yaitu rumus no. 2 (Converse -Labarre)

Dari data yang diperoleh untuk kedalaman tiang bor yang di gunakan bervariasi mulai dari 6 m sampai dengan $12 \mathrm{~m}$. Oleh sebab itu, perhitungan dimulai dengan daya dukung aksial pada kedalaman tiang $6 \mathrm{~m}, 8 \mathrm{~m}, 10 \mathrm{~m}, 12 \mathrm{~m}$, dan 16 m. Perhitungan daya dukung fondasi dapat dilihat pada tabel 7.

Tabel 6. Daya dukung fondasi

\begin{tabular}{ccccccc}
\hline Kedalaman & $\begin{array}{c}\text { Beban per kolom } \\
(\mathrm{kN})\end{array}$ & & $\begin{array}{c}\text { Daya Dukung Aksial } \\
\text { Tunggal }(\mathrm{kN})\end{array}$ & Check & Efisiensi $(\mathrm{kN})$ & Check \\
\hline 1 & 2 & 3 & 4 & 5 & 6 & 7 \\
\hline $6 \mathrm{~m}$ & 250,4226 & $>$ & 52,9087 & TIDAK OK & - & - \\
$10 \mathrm{~m}$ & 250,4226 & $>$ & 123,0237 & TIDAK OK & - & - \\
$12 \mathrm{~m}$ & 250,4226 & $>$ & 183,4476 & TIDAK OK & - & - \\
$14 \mathrm{~m}$ & 250,4226 & $<$ & 284,5760 & OK & 904,9517 & TIDAK OK \\
$16 \mathrm{~m}$ & 250,4226 & $<$ & 411,7453 & OK & 1309,3502 & OK \\
\hline
\end{tabular}




\section{Penurunan bangunan}

Penurunan bangunan ini memiliki perbedaan pada kanan dan kiri bangunan. Setelah melakukan pemeriksaan visual dari depan bangunan dapat dilihat bahwa penurunan sebelah kanan lebih kecil dibandingkan penurunan pada sebelah kiri bangunan. Oleh sebab itu diasumsikan bahwa beban bangunan yang ada di sebelah kanan ditahan oleh fondasi pada bangunan tetangga yang ada di sebelah kanan sehingga beban yang turun ke fondasi bangunan 4 lantai ini tidak 100\%. Berdasarkan asumsi perhitungan penurunan bangunan dengan fondasi yang memiliki kedalaman bervariasi dapat dilihat pada tabel 7.

Tabel 7. Penurunan bangunan

\begin{tabular}{cc}
\hline Kedalaman $(\mathrm{m})$ & Penurunan $(\mathrm{cm})$ \\
\hline 1 & 2 \\
\hline 4 & 37,05 \\
6 & 22,56 \\
8 & 16,23 \\
10 & 8,12 \\
12 & 6,10 \\
14 & 5,03 \\
16 & 2,90 \\
\hline
\end{tabular}

Berdasarkan pengamatan yang terjadi pada bangunan tersebut penurunan bangunan sebesar 18,53 cm. Berdasarkan hasil perhitungan pada tabel 8, kemungkinan yang menyebabkan terjadinya perbedaan penurunan adalah jika fondasi tiang bor ditanam sampai dengan kedalaman 8,6,dan 4 m karena penurunannya mendekati 18,53 cm. Sehingga analisis penurunan akan dilakukan untuk fondasi tiang bor pada kedalaman 8,6,dan $4 \mathrm{~m}$.

Untuk menghitung penurunan fondasi bagian kanan bangunan diasumsikan beban yang di reduksi akibat adanya bangunan tetangga sebesar 20-90\% seperti yang tercantum pada tabel 8. Dari hasil perhitungan untuk setiap reduksi beban tersebut diperoleh besarnya penurunan 4,6,dan $8 \mathrm{~m}$ dapat dilihat pada tabel 8.

Tabel 8. Reduksi beban bangunan

\begin{tabular}{cccc}
\hline \multicolumn{4}{c}{ Reduksi Beban Penurunan } \\
Reduksi beban & $4 \mathrm{~m}(\mathrm{~cm})$ & $6 \mathrm{~m}(\mathrm{~cm})$ & $8 \mathrm{~m}(\mathrm{~cm})$ \\
\hline 1 & 2 & 3 & 4 \\
\hline $0 \%$ & 37 & 23 & 16 \\
$20 \%$ & 29 & 20 & 14 \\
$40 \%$ & 25 & 17 & 12 \\
$60 \%$ & 20 & 14 & 10 \\
$80 \%$ & 16 & 10 & 7 \\
$90 \%$ & 13 & 8 & 6 \\
\hline
\end{tabular}

Dapat dilihat bahwa besarnya perbedaan penurunan pada tiang bor dengan kedalaman 4,6,dan 8 m dapat dilihat pada tabel 9, tabel 10, dan tabel 11.

Tabel 9. Perbedaan penurunan kiri dan kanan bangunan tiang bor sedalam $4 \mathrm{~m}$

\begin{tabular}{ccc}
\hline $\begin{array}{c}\text { Penurunan Tiang } \\
\text { Tanpa Reduksi }(\mathrm{cm})\end{array}$ & $\begin{array}{c}\text { Penurunan Tiang Dengan } \\
\text { Reduksi Beban }(\mathrm{cm})\end{array}$ & $\begin{array}{c}\text { Perbedaan Penurunan } \\
(\mathrm{cm})\end{array}$ \\
\hline 1 & 2 & 3 \\
\hline 37 & 37 & 0 \\
37 & 29 & 8 \\
37 & 25 & 12 \\
37 & 20 & 17 \\
37 & 16 & 22 \\
37 & 13 & 24 \\
\hline
\end{tabular}


JMTS: Jurnal Mitra Teknik Sipil

Vol. 4, No. 3, Agustus 2021: hlm 615-622

Tabel 10. Perbedaan penurunan kiri dan kanan bangunan tiang bor $6 \mathrm{~m}$

\begin{tabular}{ccc}
\hline $\begin{array}{c}\text { Penurunan Tiang } \\
\text { Tanpa Reduksi }(\mathrm{cm})\end{array}$ & $\begin{array}{c}\text { Penurunan Tiang Dengan } \\
\text { Reduksi Beban }(\mathrm{cm})\end{array}$ & $\begin{array}{c}\text { Perbedaan Penurunan } \\
(\mathrm{cm})\end{array}$ \\
\hline 1 & 2 & 3 \\
\hline 23 & 23 & 0 \\
23 & 20 & 3 \\
23 & 17 & 6 \\
23 & 14 & 9 \\
23 & 10 & 12 \\
23 & 8 & 14 \\
\hline
\end{tabular}

Tabel 11. Perbedaan penurunan kiri dan kanan bangunan tiang bor $8 \mathrm{~m}$

\begin{tabular}{ccc}
\hline $\begin{array}{c}\text { Penurunan Tiang } \\
\text { Tanpa Reduksi }(\mathrm{cm})\end{array}$ & $\begin{array}{c}\text { Penurunan Tiang Dengan } \\
\text { Reduksi Beban }(\mathrm{cm})\end{array}$ & $\begin{array}{c}\text { Perbedaan Penurunan } \\
(\mathrm{cm})\end{array}$ \\
\hline 1 & 2 & 3 \\
\hline 16 & 16 & 0 \\
16 & 14 & 2 \\
16 & 12 & 4 \\
16 & 10 & 6 \\
16 & 7 & 9 \\
16 & 6 & 10 \\
\hline
\end{tabular}

\section{Analisis}

Berdasarkan hasil pengamatan diperoleh bahwa kemiringan bangunan sebesar 18,53 cm. Berdasarkan perhitungan yang sudah diperoleh, maka hasil perhitungan akan diberikan dalam bentuk grafik agar mempermudah menyimpulkan apa yang mengakibatkan terjadinya penurunan bada bangunan tersebut.

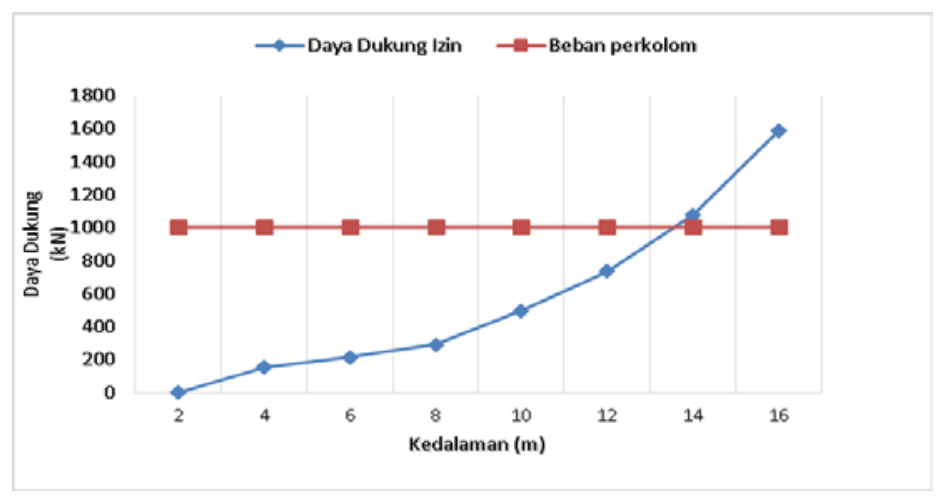

Gambar 3. Daya dukung izin vs beban perkolom

Berdasarkan grafik pada gambar 3 dapat dilihat bahwa pada tiang bor kedalaman 14-16 m tiang bor kuat menahan beban bangunan. Berdasarkan gambar 3 terlihat bahwa fondasi dimasukan kedalam 4-12 m maka daya dukung belum cukup untuk mendukung beban bangunan tersebut yang dapat mengakibatkan kegagalan tanah atau penurunan yang berlebihan. Berdasarkan pengamatan kegagalan tanah tidak terlihat, tetapi bangunan miring. Maka kemungkinan yang terjadi adalah perbedaan penurunan antara fondasi bagian kiri dan fondasi bagian kanan.

Berdasarkan analisis besar penurunan untuk fondasi kedalaman 4,6,8 m dan dengan asumsi terjadi reduksi beban pada fondasi bagian kanan bangunan akan terjadi perbedaan penurunan yang bias dilihat pada gambar 4 . 


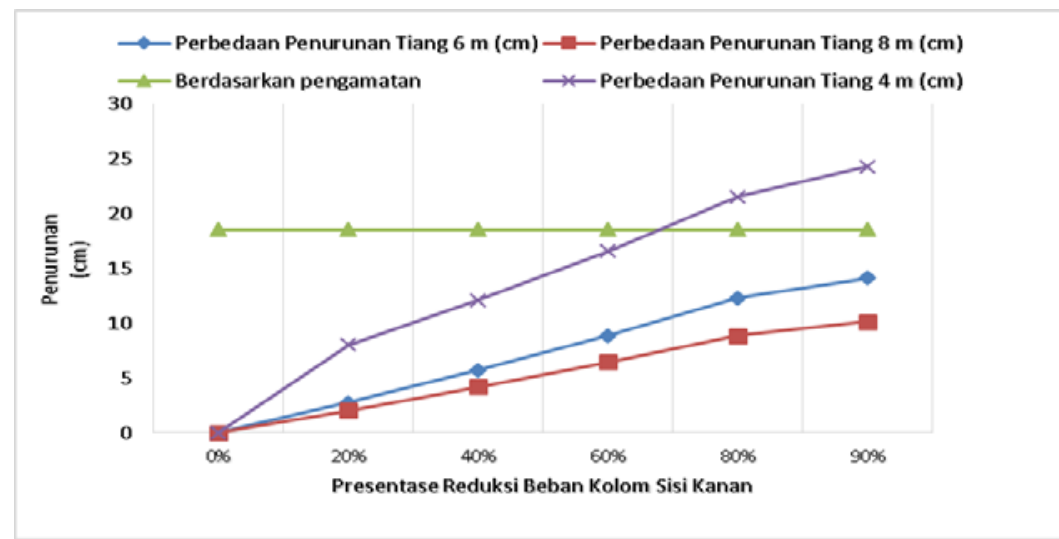

Gambar 4. Perbedaan penurunan 4m, 6m, 8m, dan hasil pengamatan

Berdasarkan grafik pada gambar 4 dapat dilihat bahwa perbedaan penurunan yang mendekati dengan hasil pengamatan adalah fondasi tiang bor dengan kedalaman $4 \mathrm{~m}$ dan reduksi beban sebesar 60-80\%

\section{KESIMPULAN DAN SARAN}

\section{Kesimpulan}

- $\quad$ Penggunaan daya dukung tanah terhadap fondasi dengan kedalaman 6m-12m tidak mampu menahan beban dari bangunan.

- $\quad$ Berdasarkan hasil perhitungan dapat disimpulkan bahwa fondasi tiang bor yang digunakan kemungkinan hanya menggunakan fondasi tiang bor pada kedalaman $4 \mathrm{~m}$ atau $6 \mathrm{~m}$ sehingga mengakibatkan penurunan yang cukup besar.

- Berdasarkan hasil pengamatan diketahui bahwa perbedaan kemiringan yang terjadi antara kiri dan kanan bangunan sebesar $18,53 \mathrm{~cm}$.

- Kemiringan bangunan dapat terjadi karena perbedaan tanah sebelah kanan dan kiri bangunan dimana tanah yang disebelah kiri bangunan lebih lembut dari sebelah kanan bangunan sehingga pada tahap pembangunan terjadi pergerakan pada tanah yang mengakibatkan kemiringan pada bangunan.

- Dari hasil pengamatan ini diperoleh bahwa analisis penurunan yang mendekati hasil pengamatan adalah tiang bor diameter 0,45 m dengan kedalaman $4 \mathrm{~m}$ dengan reduksi beban kolom sebelah kanan sebesar 60-80\% sebesar 17$22 \mathrm{~cm}$. Berdasarkan hasil perhitungan ini dapat disimpulkan bahwa kemungkinan besar fondasi yang digunakan tidak sesuai dengan yang diberitakan di gambarnya sehingga fondasi yang digunakan hanya memiliki kedalaman $4 \mathrm{~m}$

\section{Saran}

Dalam pembangunan bangunan sebaiknya dilakukan soil test dan perhitungan daya dukung tanah serta penurunan bangunan agar tidak terjadi kesalahan yang sama seperti bangunan yang dianalisis.

\section{DAFTAR PUSTAKA}

Das, B. M. (2011). Principles of Foundation Engineering. Cengage Learning.

Pranoto, Y., \& Setiabudi, R. (2017). Evaluasi Penurunan Gedung dan Metode Perbaikannya. Jurnal Teknik Mesin. Solikhati, Y. (2011). Pondasi. Konstruksi Bangunan.

Yusti, A., \& Fahriani, F. (2014). Analisis Daya Dukung Pondasi Tiang Pancang Diverifikasi dengan Hasil Uji Pile Driving Analyzer Test dan Capwap (Studi Kasus Proyek Pembangunan Gedung Kantor Bank Sumsel Babel di Pangkalpinang). Jurnal Fropil. 